\title{
Determination of the Absolute Rate Constants for Free-Radical Polymerization
}

\author{
Kuo JEN-Feng and Chen ChuH-Yung \\ Department of Chemical Engineering, National Cheng Kung University, \\ Tainan, Taiwan 700, Republic of China.
}

(Received August 27, 1980)

\begin{abstract}
The absolute rate constants for the propagation and termination of free-radical polymerization were determined by the convenient kinetic data without need for photo-illumination technique. The extent of recombination reaction occurring in the termination reactions can be obtained using the same experimental data. The homopolymerizations of styrene and methyl methacrylate are illustrated. The results obtained by this method are close to those in the literature.

KEY WORDS Method / Absolute Rate Constants / Termination Mechanism / Radical Polymerization /
\end{abstract}

It is frequently necessary to know the absolute magnitude of the individual rate constants involved in each elementary reaction of polymerization since this knowledge makes feasible a correlation of the reactivity of the species with its chemical structure.

The rate constant for the initiation reaction can be estimated under favorable conditions in experiments using inhibitors ${ }^{1}$ or by measuring the data of decomposition of the initiator. ${ }^{2}$ However, the determination of the absolute rate constants of propagation and termination reactions $\left(k_{\mathrm{p}}\right.$ and $\left.k_{\mathrm{t}}\right)$ is far from straightforward. $k_{\mathrm{p}}$ and $k_{\mathrm{t}}$ must be determined by the analysis of kinetic data obtained from steadystate and unsteady-state methods. ${ }^{3,4}$ However, $k_{\mathrm{t}}$ determined by these methods is essentially an overall value. Furthermore, for a detail study of the mechanism involved in termination, the extent of recombination and disproportionation which occur in the termination reaction should be determined. For this purpose, additional experimental work, utilizing radiation trace techniques, ${ }^{5,6}$ or gelpermeation chromatography (GPC) measurement, ${ }^{7}$ should be done. Hereafter, the extent of recombination which occurs in the termination reaction is designated as $\beta$.

In this paper we mathematically analyze the kinetic rate expression of free-radical polymerization in which possible chain-transfer reactions are assumed to be negligible. Thus, we obtain an expression which indicates the relationship for reaction conversion, number-average molecular weight, rate constants, and reaction time. Using this expression, we may simultaneously obtain the absolute constant of termination and $\beta$ from the data by the steady-state method. Meanwhile, the absolute rate constant of propagation may be obtained using the same experimental data. Finally the feasibility of this new method is tested by comparing the absolute rate constants for the homopolymerizations of methyl methacrylate and styrene obtained in this work with the values reported in the literature.

\section{THEORETICAL}

The complete reaction scheme for the free-radical homopolymerization is shown below. In this scheme, termination by primary radicals and chaintransfer reactions are all negligible.

$$
\begin{gathered}
{[\mathrm{I}] \frac{k_{\mathrm{d}}}{k_{\mathrm{i}}} 2[\mathrm{R}]} \\
{[\mathrm{R}]+[\mathrm{A}] \frac{\mathrm{P}_{1}}{k_{\mathrm{p}}}[\mathrm{P}]_{j+1}} \\
{[\mathrm{P}]_{j}+[\mathrm{A}] \frac{k_{\mathrm{tc}}}{[\mathrm{M}]_{i+j}}} \\
{[\mathrm{P}]_{i}+[\mathrm{P}]_{j} \frac{k_{\mathrm{td}}}{[\mathrm{M}]_{i}+[\mathrm{M}]_{j}}}
\end{gathered}
$$

where $[\mathrm{I}]$ and $[\mathrm{A}]$ represent the concentrations (and 
the species) of initiator and monomer, respectively. $[\mathrm{R}]$ is the concentration of initiator fragment. $[\mathrm{P}]_{j}$ and $[\mathrm{M}]_{j}$ denote the concentrations of the active and stable polymers of chain length $j$, respectively. $k_{\mathrm{tc}}$ and $k_{\mathrm{td}}$ refer to the rate constants of recombination and disproportionation, and the overall termination constant $k_{\mathrm{t}}$ is equal to the sum of $k_{\mathrm{tc}}$ and $k_{\mathrm{td}}$.

According to the scheme above, the rate expressions for each kinetic process in the chain reaction may be written as follows.

Initiation

$$
R_{\mathrm{i}}=2 f k_{\mathrm{d}}[\mathrm{I}]
$$

Propagation

$$
R_{\mathrm{p}}=-\mathrm{d}[\mathrm{A}] / \mathrm{d} t=k_{\mathrm{p}}[\mathrm{P}]_{\mathrm{o}}[\mathrm{A}]
$$

Formation of polymer radicals

$$
R_{\mathrm{ap}}=\mathrm{d}[\mathrm{P}]_{0} / \mathrm{d} t=[\mathrm{R}]_{i}-2 k_{\mathrm{t}}[\mathrm{P}]_{0}^{2}
$$

Formation of dead polymers

$$
R_{\text {dead polymer }}=\mathrm{d}[\mathrm{M}]_{0} / \mathrm{d} t=\left(k_{\mathrm{tc}}+2 k_{\mathrm{td}}\right)[\mathrm{P}]_{0}^{2}
$$

where

$$
\begin{aligned}
{[\mathrm{P}]_{0} } & =\sum_{j=1}^{\infty}[\mathrm{P}]_{j} ; \quad k_{\mathrm{t}}=k_{\mathrm{tc}}+k_{\mathrm{td}} ; \\
{[\mathrm{M}]_{0} } & =\sum_{j=1}^{\infty}[\mathrm{M}]_{j}
\end{aligned}
$$

In these rate expressions, we assume that the density of the reaction solution remains constant and that the kinetic rate constants are independent of the molecular weight of the growing chain. The longchain hypothesis is also assumed. As in most works cited in the literature, the stationary-state principle is assumed to be applicable to all growing polymer radicals. This means, $R_{\mathrm{ap}}=0$. Thus, the expression for the concentration of the total active species is,

$$
[\mathrm{P}]_{0}=\left(f k_{\mathrm{d}}[\mathrm{I}] / k_{\mathrm{t}}\right)^{1 / 2}
$$

Substitution of eq 5 into eq 2 gives,

$$
R_{\mathrm{p}}=\left(k_{\mathrm{p}} / k_{\mathrm{t}}^{1 / 2}\right)\left(f k_{\mathrm{d}}[\mathrm{I}]\right)^{1 / 2}[\mathrm{~A}]
$$

On integrating of eq 4 after $[\mathrm{P}]_{0}$ has been replaced by $\left(f k_{\mathrm{d}}[\mathrm{I}] / k_{\mathrm{t}}\right)^{1 / 2}$ we obtain,

$$
[\mathrm{M}]_{0}=(2-\beta) f[\mathrm{I}]_{0}(1-\alpha)
$$

where $\beta$ is defined as $k_{\mathrm{tc}} / k_{\mathrm{t}}$, the extent of recombination which occurs in the termination reaction. $\alpha$ is equal to $\exp \left(-k_{\mathrm{d}} t\right)$.
The number-average molecular weight of polymer may be represented as,

$$
M_{n}=\left([\mathrm{A}]_{0}-[\mathrm{A}]\right) M_{\mathrm{A}} /\left([\mathrm{P}]_{0}+[\mathrm{M}]_{0}\right)
$$

or

$$
M_{n}=[\mathrm{A}]_{0} X M_{\mathrm{A}} /\left([\mathrm{P}]_{0}+[\mathrm{M}]_{0}\right)
$$

where $[\mathrm{A}]_{0}$ is the initial monomer concentration, $M_{\mathrm{A}}$ the molecular weight of monomer $\mathrm{A}$, and $X$ is the monomer conversion defined as $\left([\mathrm{A}]_{0}-[\mathrm{A}]\right) /[\mathrm{A}]_{0}$.

Combination of eq 8 with eq 5 and 7 gives,

$$
\begin{gathered}
\left([\mathrm{A}]_{0} X M_{\mathrm{A}} / M_{n}\right) /\left([\mathrm{I}]_{0} \alpha\right)^{1 / 2}=\left(f k_{\mathrm{d}} / k_{\mathrm{t}}\right)^{1 / 2} \\
+(2-\beta)(1-\alpha)\left([\mathrm{I}]_{0} / \alpha\right)^{1 / 2}
\end{gathered}
$$

On using eq $9, k_{\mathrm{t}}$ and $\beta$ can be determined from the data of molecular weight and monomer conversion for each reaction time. Using eq 6 , the absolute rate constant of propagation $k_{\mathrm{p}}$ can then be evaluated after $k_{\mathrm{p}} / k_{\mathrm{t}}^{1 / 2}$ is determined from the slope of the plot of $R_{\mathrm{p}} v s .\left(f k_{\mathrm{d}}[\mathrm{I}]_{0}\right)^{1 / 2}[\mathrm{~A}]_{0}$.

\section{EXPERIMENTAL}

\section{Materials}

Commercially supplied methyl methacrylate was purified by washing several times in $10 \%$ aqueous sodium hydroxide, and then with distilled water for three times. After drying with anhydrous sodium sulfate, the material was fractionally distilled under $81 \mathrm{mmHg}$ of nitrogen. The fraction distilled between $39.8^{\circ} \mathrm{C}$ and $40^{\circ} \mathrm{C}$ was collected, redistilled, transferred to a high-vacuum line, and immediately degassed and placed within ampoules containing benzoyl peroxide. These ampoules containing the monomer and initiator were immersed in a wellthermostated water bath maintained at $60 \pm 0.1^{\circ} \mathrm{C}$ for proceeding polymerization. The reaction conversion was determined by conventional gravimetry. Triple samples were taken to determine each conversion. The allowable error was within $0.5 \%$ weight deviation from the mean values. Molecular weight determination of the polymer.

The average molecular weights $\left(M_{n}\right.$ and $\left.M_{w}\right)$ for poly(methyl methacrylate) were measured by GPC (Waters Associates), using five columns with the following specifications, $10^{6} \AA, \quad 10^{5} \AA, \quad 10^{4} \AA$, $2 \times 10^{3} \AA$, and $500 \AA \mu$-styragel. The carrier solvent was tetrahydrofuran (THF) whose flow rate was $0.8 \mathrm{ml} \mathrm{m^{-1 }}$ at room temperature. The molecular 
weight calibration curve was obtained using the polystyrene standards provided by Waters Associates, Inc.

\section{RESULTS AND DISCUSSION}

Table I shows the experimental results for the reaction conversion and the number-average molecular weights at various initiator concentrations and reaction times. Using the data of Table I, the plot of $\left([\mathrm{A}]_{0} X M_{\mathrm{A}} / M_{n}\right) /\left([\mathrm{I}]_{0} \alpha\right)^{1 / 2}$ vs. $(1-\alpha) f\left([\mathrm{I}]_{0} / \alpha\right)^{1 / 2}$ was obtained by eq 9 and is shown in Figure 1. The absolute rate constant of termination determined from the slope of the plot was $2.5 \times 10^{7} 1 \mathrm{~mol}^{-1}$ $\mathrm{s}^{-1}$, where the values ${ }^{8}$ of $k_{\mathrm{d}}$ and $f$ of benzoyl peroxide used for estimating $k_{\mathrm{t}}$ were $3.2 \times 10^{-6} \mathrm{~s}^{-1}$ and 0.6 , respectively. $\beta$ determined from the intercept of the same plot was found to be $62 \%$. In order to obtain the rate constant of propagation, the plot of $[\mathrm{R}]_{\mathrm{pi}} /[\mathrm{A}]_{0} v s$. $[\mathrm{I}]_{0}^{1 / 2}$ was made and is shown in Figure 2. The value of $k_{\mathrm{p}} / k_{\mathrm{t}}^{1 / 2}$ of methyl methacrylate determined from the slope in Figure 2 was 0.140 . Thus, the absolute propagation rate constant

Table I. Summary of experimental data for the benzoyl peroxide initiated polymerization of methyl methacrylate at $60^{\circ} \mathrm{C}$

\begin{tabular}{|c|c|c|c|}
\hline $\begin{array}{c}\mathrm{Bz}_{2} \mathrm{O}_{2} \times 10^{3} \\
\left(\text { at } 60^{\circ} \mathrm{C}\right)\end{array}$ & $\begin{array}{l}\text { Reaction } \\
\text { time }\end{array}$ & $\begin{array}{c}\text { Reaction } \\
\text { conversion, } \\
X\end{array}$ & $\begin{array}{l}\text { Number-average } \\
\text { molecular weight }\end{array}$ \\
\hline M & $\min$ & $\%$ & $M_{n} \times 10^{-6}$ \\
\hline \multirow[t]{5}{*}{0.5} & 30 & 1.54 & 5.241 \\
\hline & 60 & 3.05 & 5.210 \\
\hline & 90 & 4.52 & 5.164 \\
\hline & 120 & 5.97 & 5.130 \\
\hline & 150 & 7.39 & 5.096 \\
\hline \multirow[t]{5}{*}{1.0} & 30 & 2.17 & 3.695 \\
\hline & 60 & 4.28 & 3.656 \\
\hline & 90 & 6.34 & 3.622 \\
\hline & 120 & 8.34 & 3.584 \\
\hline & 150 & 10.28 & 3.545 \\
\hline \multirow[t]{4}{*}{5.0} & 30 & 4.79 & 1.632 \\
\hline & 60 & 9.33 & 1.594 \\
\hline & 90 & 13.62 & 1.556 \\
\hline & 120 & 17.69 & 1.521 \\
\hline \multirow[t]{3}{*}{10.0} & 30 & 6.71 & 1.143 \\
\hline & 60 & 12.93 & 1.105 \\
\hline & 90 & 18.71 & 1.069 \\
\hline
\end{tabular}

obtained was $705.61 \mathrm{~mol}^{-1} \mathrm{~s}^{-1}$. Table II lists the rate constant magnitudes obtained in this work and selected from the literature. ${ }^{9-13}$ It was found that our results agree fairly well with those in the

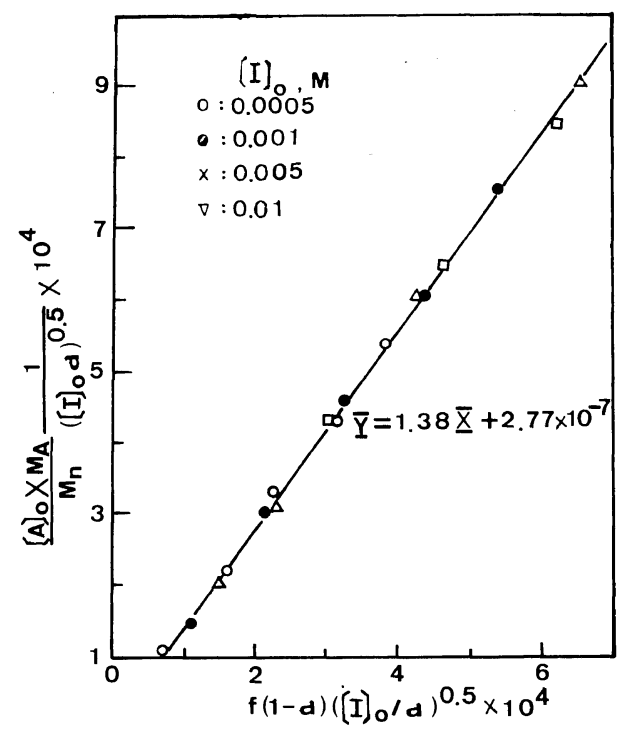

Figure 1. Determination of $\left(f k_{\mathrm{d}} / k_{\mathrm{t}}\right)^{0.5}$ and $k_{\mathrm{tc}} / k_{\mathrm{t}}$ on the methyl methacrylate system at $60^{\circ} \mathrm{C}$.

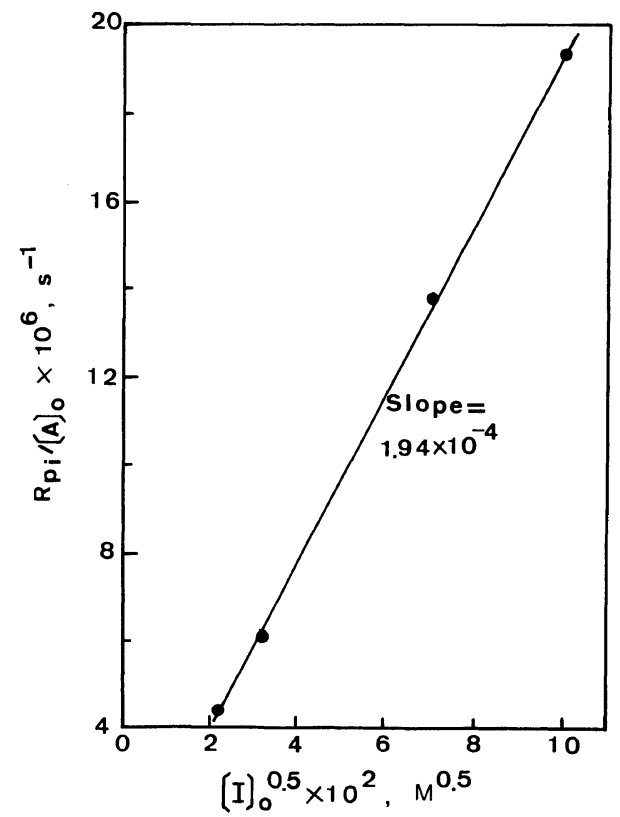

Figure 2. The plot of $R_{\mathrm{pi}} /[\mathrm{A}]_{0} v s .[\mathrm{I}]_{0}^{0.5}$ for determining $\left(f k_{\mathrm{d}}\right)^{0.5} k_{\mathrm{p}} / k_{\mathrm{t}}^{0.5}$ of the methyl methacrylate system at $60^{\circ} \mathrm{C}$. 
Table II. Absolute rate constants and fraction of combination occurring in the termination reaction of free-radical polymerization of methyl methacrylate at $60^{\circ} \mathrm{C}$

\begin{tabular}{lcccc}
\hline & $k_{\mathrm{t}}$ & & $k_{\mathrm{p}}$ & \\
\cline { 2 - 3 } & $1 \mathrm{~mol}^{-1} \mathrm{~s}^{-1}$ & & $1 \mathrm{~mol}^{-1} \mathrm{~s}^{-1}$ & \\
\hline This work & $2.5 \times 10^{7}$ & & 705.6 & $62 \%$ \\
Litterature & $3.7 \times 10^{7 \mathrm{a}}$ & & $734^{\mathrm{a}}$ & $60 \% \mathrm{o}$ \\
& $9.3 \times 10^{6 \mathrm{c}}$ & & $367^{\mathrm{c}}$ & $57.5 \% \mathrm{~d}$ \\
& $1.8 \times 10^{7 \mathrm{e}}$ & & $705^{\mathrm{e}}$ & $\cdots$ \\
\hline
\end{tabular}

a ref 9 .

b ref 10 .

c ref 11 .

d ref 12

e ref 13.

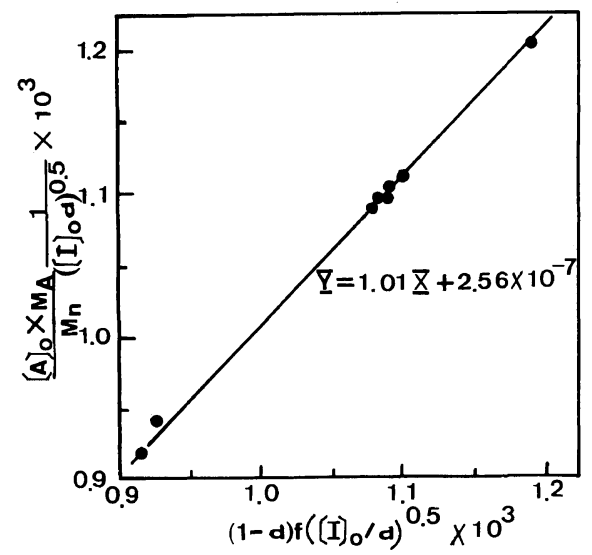

Figure 3. Determination of $\left(f k_{\mathrm{d}} / k_{\mathrm{t}}\right)^{0.5}$ and $k_{\mathrm{tc}} / k_{\mathrm{t}}$ on the styrene system at $60^{\circ} \mathrm{C}$.

literature.

We also tested the absolute rate constants in the styrene polymerization. Data on styrene polymerization at $60^{\circ} \mathrm{C}$ have been reported by May-Smith ${ }^{14}$ and Kuo-Chen. ${ }^{7}$ Figures 3 and 4 show the individual plots of $\left([\mathrm{A}]_{0} X M_{\mathrm{A}} / M_{n}\right) /\left([\mathrm{I}]_{0} \alpha\right)^{1 / 2} \quad v s$. $(1-\alpha) f\left([\mathrm{I}]_{0} / \alpha\right)^{1 / 2}$ and $R_{\mathrm{pi}}[\mathrm{A}]_{0} v s$. $[\mathrm{I}]_{0}^{1 / 2}$. The results for the rate constants of termination and propagation and the extent of recombination which occurred in the termination reaction are given in Table III. From this table, our observed values, within the experimental error, were found to agree with those in the literature.

In consideration of the above results comparable favorably with those obtained by classical methods,

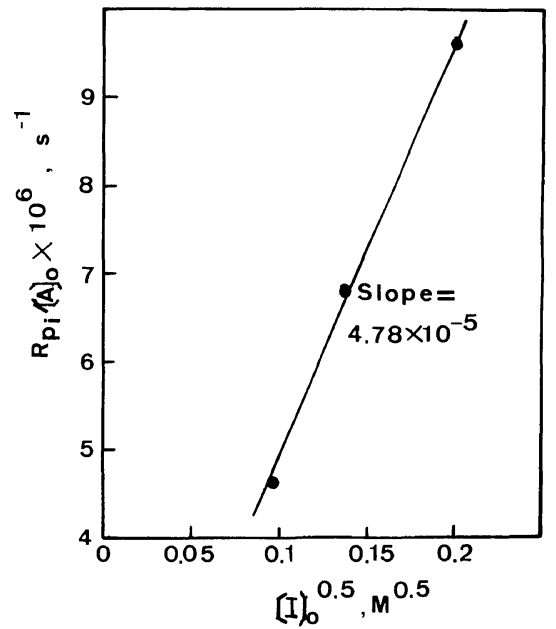

Figure 4. The plot of $R_{\mathrm{pi}} /[\mathrm{A}]_{0} v s$. [ $[\mathrm{I}]_{0}^{0.5}$ for determining $\left(f k_{\mathrm{d}}\right)^{0.5} k_{\mathrm{p}} / k_{\mathrm{t}}^{0.5}$ of the styrene system at $60 \mathrm{C}$.

Table III. The absolute rate constants and fraction of combination occurring in the termination reaction of the free-radical polymerization of styrene at $60^{\circ} \mathrm{C}$

\begin{tabular}{lllll}
\hline & \multicolumn{1}{c}{$k_{\mathrm{t}}$} & & $k_{\mathrm{p}}$ & \\
\cline { 2 - 3 } & $1 \mathrm{~mol}^{-1} \mathrm{~s}^{-1}$ & & $\beta \mathrm{mol}^{-1} \mathrm{~s}^{-1}$ & \\
\hline This work & $2.94 \times 10^{7}$ & 187.1 & $99 \%$ \\
Literature & $2.9 \times 10^{7 \mathrm{a}}$ & $145^{\mathrm{a}}$ & $100 \% \mathrm{~b}$ \\
& $3.6 \times 10^{7 \mathrm{c}}$ & $176^{\mathrm{c}}$ & $\cdots$ \\
\hline
\end{tabular}

\footnotetext{
a ref 3 .

b ref 11 .

c ref 15 .
}

the advantage of our method is that the absolute rate constants and the extent of recombination which occurred in the termination reaction are determined simply by the use of steady-state kinetic data and measurements of number-average molecular weight of the formed polymers.

\section{REFERENCES}

1. P. D. Bartlett and H. Kwart, J. Am. Chem. Soc., 68, 1686 (1946).

2. R. H. Gobran, M. B. Berenbaum, and A. V. Tobolsky, J. Polym. Sci., 46, 431 (1960).

3. C. Walling, "Free Radicals in Solution," John Wiley \& Sons, Inc., New York, N.Y., 1957, Chapters 3-5.

4. P. J. Flory, "Principles of Polymer Chemisty," 
Cornell University Press, Ithaca, 1953, Chapter IV.

5. F. Deschrijver and G. Smets, J. Polym. Sci., A-1, 4, 2201 (1966).

6. F. R. Mayo and C. Walling, Chem. Rev., 46, 231 (1950).

7. J. F. Kuo, C. Y. Chen, and J. M. Jiang, Chemistry (The journal of The Chinese Chemical Society, Taiwan, China), 4, 103 (1978).

8. F. R. Mayo, R. A. Gregg, and M. S. Matheson, J. Am. Chem. Soc., 73, 1691 (1951).

9. D. Margerison and G. C. East, "Introduction to Polymer Chemistry," Pergamon Press, New York, N.Y., 1967.
10. G. V. Schulz, G. Henrici-Olive, and S. Olive, Makromol. Chem., 31, 88 (1959).

11. M. S. Matheson, E. E. Auer, E. B. Bevilacqua, and E. J. Hart, J. Am. Chem. Soc., 71, 497 (1949).

12. A. Ayrey and C. G. Moore, J. Polym. Sci., 36, 4 (1959).

13. M. Charton and A. J. Capato, J. Polym. Sci., A, 2, 1321 (1964).

14. J. A. May and W. B. Smith, J. Phys. Chem., 72, 216 (1968).

15. J. C. Bevington and H. W. Melville, J. Polym. Sci., 12, 449 (1954). 